\title{
THE APPLICATION OF A LARGE GROUP INTERVENTION METHOD BASED ON THE ASSET-BASED APPROACH: A REPOSITIONING OF TRAINING IN COMMUNITY DEVELOPMENT
}

\section{JBS Nel}

\section{INTRODUCTION}

Since the abolition of apartheid in South Africa in 1994 the policies and practices of social and community development has gained wide recognition as the most appropriate way to address inequities in South African society. As a result, a wide variety of community training programmes and models have been introduced and a great deal of resources have been invested in the training of students in community development. However, up to now the outcomes have mostly been disappointing. Most training programmes are based on the so-called top-down "expert approach," with deficiencies or deficits as the point of departure and an emphasis on felt needs, problems and the role of the community developer as expert. This is problematic because the concept of felt needs is inadequate for contemporary community development practice and a needs-assessment methodology is not an appropriate basis for programme design. Felt needs are products of a pastto-present orientation in which attempts are made to fix the past. Such an approach is incapable of addressing South Africa's social and economic problems (Wade, 1989).

The assets-based approach presents a viable alternative. It focuses on assets not needs. It is a capacity-building approach which relies on visionary community-based leadership, where "anticipatory" needs determine what is required to be done to move towards an anticipated future. Anticipatory needs are products of a present-to-future orientation; they are visionary and inspirational in nature (Green \& Haines, 2002; Kretzmann \& McKnight, 1993). The ABCD approach includes whole system processes to engage and motivate large groups of people in community actions, geared towards self-reliant sustainable development (Bunker \& Alban, 1997; Holman \& Devane, 1999; Weisbord \& Janoff, 2000). These processes tend to cultivate the selfimage of citizens and energise stakeholders to take ownership of the development of their communities. The approach is also holistic, integrated and interdisciplinary in nature. It was incorporated into the Social Work masters' curriculum at the University of Johannesburg (previously the Rand Afrikaans University) during 2004. Once trained in ABCD, the students were required to implement the approach in various rural and urban communities as part of the fieldwork requirements of the course. The lecturers evaluated the outcomes of the students' ABCD projects by studying student reports and interviewing students about their experience of ABCD.

\section{THEORETICAL ORIGINS OF ABCD}

$\mathrm{ABCD}$ is strengths-based and, as such, presents a radical alternative to many current intervention models, which are largely deficits-focused. It questions

“... the dominant deficiency-based mental health paradigm that pigeonholes people in terms of pathology and assigns them disempowering labels; anti-oppressive practice models that construe clients as oppressed and immediately engender feelings of powerlessness; and rigid mindsets such as positivism, ardent feminism and structuralism that lead practitioners to approach the helping situation with preconceived ideas that influence the way they listen to, hear and interpret the client's story and thus the way in which they design their interventions" (Gray \& Collett van Rooyen, 2002:193). 
Gray and Collett van Rooyen (2002) suggest that strengths-based approaches include narrative and empowerment models, brief solution-focused therapy, assets-based community development and inductive social policy. Citing Hollis (1966) and Perlman (1957), they claim that the strengths perspective is not new to social work, but observe that deficits-based approaches are more common in practice.

In many ways, strengths or assets-based approaches are eclectic in that they have their theoretical origins in various, but related, fields. One important influence is humanistic psychology with its emphasis on phenomenological approaches to personal development, which flourished in the late 1950s and throughout the 1960s in North America, where Carl Rogers developed Victor Frankl's and Abraham Maslow's ideas of human beings' capacity for self-actualisation. Rogers translated these ideas into a humanistic client-centred approach in psychology in the belief that "the individual has a sufficient capacity to deal constructively with all those aspects of his life which can potentially come into conscious awareness. This means a meaningful demonstration of the counsellor's acceptance of the client as a person who is competent to direct himself" (Rogers, 1989:24). Rather than focus on behavioural change, as was the way of the dominant behaviourist paradigm, he emphasised the importance of the client-therapist relationship, where core conditions fostering trust should be created for individuals to take control of their lives; to realise and exercise the power within (Du Toit, Grobler \& Schenk, 1998). For Rogers, the tendency to strive for self-actualisation is the human being's strongest survival instinct (Rogers, 1989:488).

Another major influence comes from the field of organisational psychology, where these ideas have been transferred to strengths-based management in for-profit and not-for-profit organisations (Senge, 1999; Wheatley, 1999). Large group intervention methods have been adapted from these strategies of interpersonal and organisational development and applied successfully in community development (Bunker \& Alban, 1997; Holman \& Devane, 1999). They suited policy makers in the third world who saw value in self-reliant participatory development strategies in recognition that governments by themselves could not achieve large-scale social development (Burkey, 2000; Chambers, 1983; Freire, 1994). They have also been successfully applied with poor and marginalised populations or communities in first world countries such as North America and Australia (Green \& Haines, 2002; Kretzmann \& McKnight, 1993).

In short, $\mathrm{ABCD}$ advocates a range of strategies aimed at developing the capacities and assets of communities and people. Given the constitutional changes in philosophy and mission embraced in developmental social welfare policies, the basic tenets of which are human rights and social justice (White Paper for Social Welfare, 1997), ABCD is seen as the intervention of choice for South Africa.

\section{CHANGES IN GLOBAL PARADIGMS AND ORGANISATIONAL MANAGEMENT}

Table 1 summarises the major changes in global development paradigms in the "emerging world" (Wheatley, 1999). To understand the relevance of large group intervention methods such as $\mathrm{ABCD}$, these changes taking place worldwide must be understood for they have an impact on economic and political relationships, social development, civil leadership, the flow of information, and role of the community in social change.

As shown in Table 1, following the Second World War, governmental and corporate structures were especially characterised by an Industrial Paradigm. Within this paradigm economic development was seen as equal to the expansion of large corporate operations and new jobs were created by these large corporate expansions, while the nation state framed and bound industrial development. The driving characteristics of business were mass production, quantity, basic 
resource conversion, producer focused and vertically structured. In this paradigm national security in most cases defined the political agenda and competition was based on success at the top (Cronjé, Du Toit \& Motlatla, 2004; Smit \& Cronjé, 2000; Wheatley, 1999).

TABLE 1

CHANGES IN GLOBAL PARADIGMS: THE EMERGING WORLD

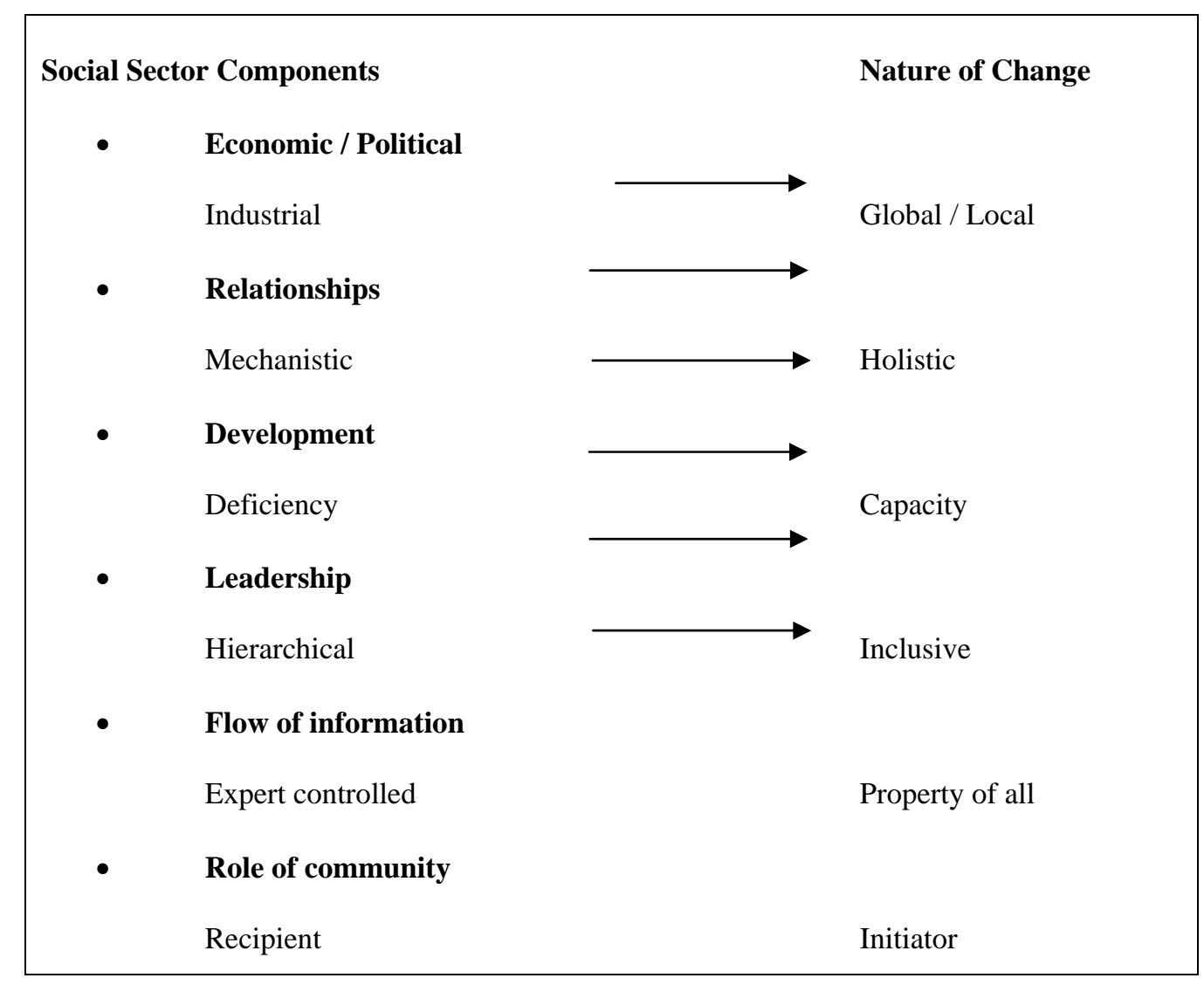

The corporate and post-war world viewed relationships in a mechanistic way, where the focus fell on things and parts. Analysis was the key way of approaching issues and structures were divided into sections and sectors to make management by analysis easier (Wheatley, 1999; McLagan \& Nel, 1995).

Because of hierarchical structures and greater specialisation, information was usually funnelled from the top to the bottom of the structure and was only given on a need to know basis, where large numbers of managers decided what information people were entitled to (Wheatley, 1999; McLagan \& Nel, 1995).

The community was seen as a bowl into which policies and projects were dumped. Communities were also frequently furnished with the same policies, no matter what their true needs or structures were (Sunter, 1999). 
Development in corporations and communities was deficiency-based, and usually focused on what was wrong. Problem-solving was focused on fixing the deficiencies of yesterday. Development efforts also focused on physical capital, where money, tools or any other physical resources were seen as the medium through which development takes place (Kretzmann \& McKnight, 1993; Green \& Haines, 2002).

Leadership structures followed a vertical top-down, hierarchical model. The leader's role was seen as being prescriptive, controlling and exclusive. People and workers were not trained according to their potential with an eye to the future; they were trained to do what they already did, only better (Wheatley, 1999).

Because of social changes, practical difficulties and limits inherent in the industrial management style and structure, certain changes have been taking place in organisations, communities and, therefore, society as a whole. The first movement taking place is that from an Industrial paradigm to a Global/Local paradigm. This change is occurring, to a large extent, partly due to social changes moving towards a greater emphasis on human rights and freedom, as well as booms in information technology and micro-electronics. This has led to major changes in both community and organisational structures. Through technology, information is disseminated at all levels of the organisation and community; and therefore everybody becomes part of the decision-making process. This leads to the fact that power is thus vested at every level in today's organisations (Helgesen in Hesselbein, Goldsmith, \& Beckard, 1996:21; Wheatley, 1999).

This paradigm sees economic development as the outcome of communities creating their own quality, nurturing capability, and human potential and relationships. This paradigm sees national boundaries and the nation state as much less relevant. In this paradigm new jobs have been created, mostly in expanding small and medium-size firms. The driving characteristics of business in this paradigm are niche markets, targeting quality, a focus on end products and consumers, and horizontal structures driven by production. National security doesn't influence the political agenda as strongly as before and it is unclear what actually does. Competition is also based not on success at the top, but success at the bottom (Sunter, 1999; Wheatley, 1999).

In this paradigm emerging relationships are organic, holistic, quality relationships, which have as their focus integrative analysis and production. Information is seen more as the property of all. The role of the community is also changing. Instead of being at the bottom of the policy path, the community is more frequently at the centre of the arena of control, as well as the initiator of programmes and policies. Policies are also frequently more heterogeneous, varying from community to community. Emerging development is more capacity-based and focuses on creating the future. The emphasis has shifted from physical capital towards social and environmental capital as the main catalysts for change and development. New organisational structures are becoming flattened, focusing on creating webs of inclusion on horizontal levels. Leadership focus has shifted to interconnection and responsibility, and recognises the human factor and tries to reconcile it with efficiency. The continued development of people and personnel focuses on anticipatory learning, where people are educated according to their anticipated growth and function in the future, not just on the basis of what they presently do. Leadership in this new paradigm also focuses more on the development of vision, giving everyone involved a voice (Cronjé et al., 2004; Schultz, Bagraim, Potgieter, Viedge \& Werner, 2003; Wheatley, 1999).

Charles Hardy (in Hesselbein et al., 1996:5) writes that organisations will be very different in the future, much more like networks and machines. He explains that industrial organisations were created to eliminate mistakes, which required extensive and expensive management structures. Unfortunately, strong control meant very little experimentation and learning. New organisations adopt the attitude that "individuals or groups have to be trusted to deliver until it is clear that they 
cannot do so", instead of deciding beforehand that they will make mistakes and should, therefore, be stopped. The new organisation allows mistakes and starts evolving more effectively, like an organic creature.

The implications are that communities will also have to start producing individuals who can function in these new organisations, who can connect in flexible and web-like organisational structures, where connection and evolution are more important than control. Resources will flow to those communities that produce individuals who can connect and operate in these new structures, in this new paradigm. Therefore, communities who can maximise and focus on skills and the capacity-building of individual members will survive and those who cannot will die.

Peter Senge (1999), in his seminal work, The fifth discipline, argues that the successful organisation/community of the future will take the form of a "learning organisation/community," which will have to practise what he calls "the five learning disciplines," in order to be successful and survive.

The first discipline is that of personal mastery. By mastery he means a special level of proficiency. People with high levels of personal mastery have the ability to consistently realise the results that matter most deeply to them. Personal mastery is the discipline of continually clarifying and deepening personal vision, of focusing energies, of developing patience and of seeing reality objectively. In a sense, this is capacity development of community/organisation members.

The second discipline is that of mental models. Mental models are deeply seated assumptions, generalisations, or even pictures or images that influence how people understand the world and how they take action. The discipline of mental models starts with teaching people in organisations and communities to reveal their pictures of the world and to hold them up to rigorous scrutiny. It includes being able to carry on meaningful conversations that balance inquiry and advocacy, where people reveal their own thinking effectively and open that thinking to the influence of others.

The third discipline is that of building a shared vision. The practice of shared vision involves the skills of unearthing shared visions of the future, which foster genuine commitment and ownership rather than compliance. While mastering this discipline, leaders learn the counter-productiveness of trying to dictate a vision, no matter how heartfelt.

The fourth discipline is team learning. This discipline involves creating teams, in which the combined performance and intelligence of the teams exceeds that of the individual members. This discipline starts with dialogue, the capacity of the members to suspend assumptions and enter into a genuine process of "thinking together". The discipline of dialogue also involves learning how to recognise the patterns of interaction in teams that undermine learning. Peter Senge (1999:233-269) is of the opinion that team learning is a vital aspect, since teams, not individuals, are the fundamental learning units in modern organisations and communities.

The fifth discipline, and according to Senge the most important, is systems thinking. Organisations and communities are parts of systems. Because people's natural tendency is to focus on the small parts of the system, problems do not seem to get solved. Systems thinking provides a set of tools that helps people in organisations and communities to focus on the whole, consisting of different parts, instead of focusing on only one part of the system.

CONTRASTING NEEDS AND ASSETS-BASED COMMUNITY DEVELOPMENT

Professionals working in communities seek solutions by taking one of two divergent paths. The first, which begins by focusing on a community's needs, deficiencies and problems, is still, by far, the most frequented path and commands the vast majority of financial and human resources. The 
second path that may be taken is a path on which there is a clear commitment to discovering the capacities and assets of a community (Kretzmann \& McKnight, 1993:1-2).

According to Wade (1989), as part of the field's early conceptualisation, the emphasis on felt needs and problems was an important principle in community development during the 1920s and 1930s. Felt needs and problems has become such a basic element of community development that an activity that does not address a felt needs issue is not considered by most professionals to be proper community development. "Felt needs" refers to the process of assessment, setting priorities and designing programmes based on people's definition of their community's problems. Because it was an effective means to develop a programme, defining needs became the basis for specifying programme development objectives in most community development models. It is believed that this approach leads communities to discover their needs and deficiencies. From this, they form a mental map of their community, which relays a part of the truth, but not the whole truth.

Once a community accepts these negative images about itself, it starts addressing its needs through deficiency-oriented policies and programmes, often funded by outside organisations that teach the community about the nature and extent of its problems. As a result, many communities of lower income are now environments of service, where their behaviours are affected because residents come to believe that their well-being is reliant on external sources. They start to see themselves as people with special needs, which can only be provided for by outsiders. They also become consumers of services, with no incentive to become producers. Residents begin to accept that map as the only guide to the reality of their lives. They think of themselves and their neighbours as fundamentally deficient, victims incapable of taking charge of their lives and of their community's future.

According to Kretzmann and McKnight (1993:4-5) the following consequences also flow from the power of the needs map:

- Viewing a community as a nearly endless list of problems and needs leads to a fragmentation of efforts to provide solutions, and denies the community the wisdom that regards problems as intertwined and as symptoms. In fact, the deficiency model denies the community's own problem-solving capacities;

- Targeting resources, based on the needs, tends to direct funding not to residents but to service providers;

- Providing resources, based on needs and problems, may create the perception that only experts can provide real help;

- Using a needs map for raising funds almost always ensures a deepening of the dependency cycle, since funding will not come unless problems are worse than they were last year;

- Reliance on needs maps as policy guides will ensure a maintenance and survival strategy, targeted at isolated individual clients, instead of a development plan that can involve the energies of the whole community;

- The fact that a needs focus guarantees only maintenance and survival contributes to feelings of hopelessness in communities.

The deficiency-based approach is not designed to bring about change, but to improve community services, facilities and people's lives (Wade, 1989). The intention is to provide individuals and groups who are "left out", with fuller access to the benefits of a democratic, industrial society. Wade (1989) said: "The central goal is not change, but rather it is improving a community's 
services, facilities, living conditions and material well-being and upgrading the quality of social amenities". Felt needs and problems identify perceptions of past problems as manifested in the present. Wade (1989) is of opinion that, by connecting the present to the past, a development process based on felt needs results in an effort to have a future that is like the past, minus the problems. The result is an emphasis on problem solving to eliminate perceived deficiencies in various aspects of community life.

The alternative path to take in community development is one that is rather based on the anticipatory needs, capacities, skills and assets of residents and their communities. According to Kretzmann and McKnight (1993), one of the reasons for shifting to a capacity-oriented emphasis is that historical evidence indicates that significant community development only takes place when local community members are committed to investing themselves and their resources in the effort. This explains why communities are never built from the top down, or from the outside in. The second is that in our modern world the prospects of outside help are bleak and therefore communities cannot always rely on outside help anymore. It is increasingly futile to wait for significant help to arrive from outside the community. A well-known fact is that development must start from within the community. What community leaders also discover is that wherever there are effective community development efforts, those efforts are based upon an understanding, or map, of the community's assets, capacities and abilities.

A thorough map of those assets begins with an inventory of the gifts, skills and capabilities of the community's residents. The map also includes a survey of churches, clubs and cultural groups, as well as local institutions, such as schools, libraries, businesses, hospitals, etc. It is clear that even the poorest communities are places where individuals and organisations represent resources upon which to rebuild. The key to neighbourhood regeneration, then, is to locate all the available local assets, to begin connecting them with one another in ways that multiply their power and effectiveness, and to begin harnessing those local institutions that are not yet available for local development purposes (Kretzmann \& McKnight, 1993; Green \& Haines, 2002).

In summary the three main aspects of the asset-based approach are:

- It is asset based, which means that the development strategy starts with what is present in the community, the skills of residents, its associations and its institutions. It does not start with what is absent, what is problematic or what the community needs.

- Because of its strong focus on assets, it is internally focused. This means that the development strategy concentrates firstly on the agenda-building and problem-solving capacities of local residents, associations and institutions. This internal focus does not mean that the importance or use of outside resources are neglected or denied, but it does mean that the focus lies on the primacy of local definition, investment, creativity, hope and control.

- If the community development process is asset-based and internally driven, it will, in many ways, be primarily "relationship driven". This means that one of the central challenges of asset-based community development is the constant building and rebuilding of relationships between and among local residents, associations and institutions (Kretzmann \& McKnight, 1993:5-10).

This asset-based approach has had many critics, especially in the Third World, since it is based mostly on work in first world countries, particularly in the United States. Yet it contains all the elements, and more, that have been emphasised in third world development. Development must be internally focused, meaning that it should be community-driven and owned. An asset-based focus also has the added benefit of empowering and creating positive images within communities about 
themselves and what they have to offer, something which development has not always done in the past. Powers (2001) is of the opinion that community work has not purely been the expert model, but neither has it been the community-based co-learning, co-creating model that embraces the knowledge within the community members in full partnership. In a conference paper he stated: "Among the significant problems facing society today are challenges of creating genuine learning communities, encouraging lifelong learning, finding effective ways to overcome barriers to change, and building greater social and human capital in our communities." This kind of community could only be established if community work could be more asset-based in approach, utilising large groups and whole system intervention methods and processes.

\section{WHOLE SYSTEM INTERVENTION}

Large group or whole system interventions and processes are used in the asset-based approach and form the basis of the asset-based approach in community development. Whole system processes for organisational and community change, or large group interventions (the term often used in organisational development), are methods for involving the whole system, internal and external, in the change process.

Firstly, the aims, background, features, principles, roles and methods of the large group change methods will be discussed. Secondly, one of the methods used in this approach, namely Vision to Action: Take Charge Too, will be discussed briefly.

\section{AIMS AND BACKGROUND OF LARGE GROUP CHANGE METHODS}

Large group interventions for organisational and community change are methods for involving the whole system in the change process, by deliberately involving a critical mass of people affected by change, both inside the organisation/community (employees, management, residents) and externally (suppliers, customers, other communities, organisations, etc.) (Bunker \& Alban, 1997:xvi). The large group methods, according to Holman and Devane (1999:vii), are for practitioners who want their organisation or community to commit to a shared vision of the future; operate from the "big picture"; make change happen; seek responsibility and take initiative; and use their creative powers to their fullest potential. These proven systematic methods "create high energy and yield extraordinary, sustainable results" (Holman \& Devane, 1999:vii). These change methods are based on two powerful assumptions, namely high involvement and a systemic approach to improvement (Holman \& Devane, 1999:6). These two authors are of the opinion that practitioners involving people in a systematic way is the key to high leverage. These methods are bottom-up approaches, which are consistent with community development principles and practices.

According to Bunker and Alban (1997:11), large group interventions emerged at the confluence of three intellectual traditions, namely social psychology, psychoanalytic theory and systems theory, as applied to organisations. Other important contributions also came from organisational development, community development, Total Quality, social science, the wisdom of indigenous cultures and studies of intelligence, creativity and the arts (Holman \& Devane, 1999:ix).

The large group change methods offer approaches to succeed in an environment in which the only reliable expectation is change. Their underlying assumption is that turbulence is to be expected and can be successfully addressed by groups that are prepared. Holman and Devane (1999:3) say these methods prepare us for tomorrow by helping us learn to "surf the waves" of change. They acknowledge an important fact of change, namely that to involve greater numbers of people than before in a major change effort may push some people beyond their comfort zone. These methods are designed to help organisations and communities develop effective plans for their future, 
develop structures to help implement their plans for the future, and to address complex, important issues that are not directly related to planning or structuring (named "adaptable methods").

Some of the most commonly recognised whole system methods from an organisational development approach include the Search Conference, Future Search, the Conference Model, Participative Design, Real Time Strategic Change, Open Space Technology, Appreciative Inquiry and Vision to Action: Take Charge Too (Holman \& Devane, 1999). Variations on these methods and others are exploding as community and organisational change facilitators adapt and create ways to involve people from an increasingly diverse range of communities and organisations.

The methods have the following characteristics in common: they consist of large groups, from 30 to 300 plus, the focus is on the change of whole systems (referring to all sections and levels of the community and being interdisciplinary in nature), they accept collaboration as a core value, the logistics are more or less the same, namely round tables, people working in small groups, the sharing of information with other groups, the use of a planning group (steering committee), "getting the system in the room", the facilitator plays a key role, and people involved must have respect for decisions made in the large-group setting (Bunker \& Alban, 1997; Holman \& Devane, 1999).

The benefits of engaging the larger community, i.e. those affected by current events, are that it builds commitment and capacity for change from the top down and the bottom up. It ultimately takes less time and is more efficient. Active participation and involvement of community members provide greater and quicker access to information - information necessary to create action for change. In addition, the diversity found in the whole system creates synergy when the factions come together as a community.

\section{FEATURES AND PRINCIPLES OF LARGE GROUP INTERVENTIONS}

According to Bunker and Alban (1997:xvi), these systems-based, change-oriented methods allow for active and authentic participation in the following areas:

- Understanding the need for change;

- Analysing the current reality and deciding what needs to change;

- Generating ideas about how to change the existing ways things are done; and

- Implementing and supporting change and making it work.

Other distinguished features of large group change methods are the following:

- Based on open systems theory and bringing the whole system together to plan with people;

- Committed to meaningful participation and engagement of the whole;

- Learning about the community as a system - a focus on interconnections and relationships;

- Focused on change efforts involving the future or strategic direction (anticipatory learning);

- A generation of useful and necessary information and data from internal and external stakeholders and residents; relying on and valuing the information that community citizens have (the establishment of an underlying research base);

- Purposeful widespread sharing of the information and data generated within the whole community;

- Broadly shared accountability and responsibility of the whole system by those in leadership; 
- Potential for simultaneous basic change;

- Based on the premise that resources and capacities exist upon which to build the future;

- Experts are replaced by one who assists in structuring and facilitating the collection of data, its analysis, and taking of action;

- It is a developmental process; and

- Collaborative learning (co-learning) process (Bunker \& Alban, 1997).

According to Bunker and Alban (1997:217-227), important principles of whole group processes to engage the community as a system are the following:

- Value participation and meaningful engagement: When people possess important information about a system and are allowed to become collaboratively and fully engaged with others around these issues, they become highly motivated to take responsibility for change and improvement.

- Select and frame the right issue: The issue must be important enough so that a critical mass of people has information to share on the subject as well as a strong desire to influence it. In addition, these events should be seen as part of a long-term change process, and not just as isolated, once-off events. For example, a community presented violence as an issue. Once the planning team had discussed the matter, they arrived at the theme for the future: "Building a community free from fear," which meant much to the community because it focused on what they most desired. This broader purpose helped the group to move from simply controlling violence to supporting and strengthening the community and its members.

- Start with a planning group: All change efforts start with a planning and design group. The moment a group starts planning, the change process has started, because people are already engaged in important discussions. A planning team should consist of at least some of the stakeholders, and the structures required for follow-up must be decided upon so that they are actually set in motion before the conference even begins.

- Select the right people: A major task of the planning group is to help frame the issue into a purpose statement for the meeting and to then decide who is required to achieve this purpose. Bunker \& Alban (1997:220) state that most groups, at least initially, think too narrowly about who should participate. Some questions could be asked to broaden the scope: Who does this issue affect? Who has a stake in the issue? Who has information on the issue? Who would be angry if they were not invited? Whose influence and perspective are important?

- Structure for good conversation: It is of crucial importance to make sure that meaningful conversations take place. The goal is to help people to recognise multiple perspectives of an issue. These quality conversations need to occur in mixed groups around a table in stakeholder groups with sources (customers, suppliers, regulators) who bring information and within the larger group.

- Allow time for reflection and creative breakthroughs: Time must be created for reflection, or as Weisbord and Janoff (2000:180) called it, "soak time.” Bunker and Alban (1997:224) say that major breakthroughs occur when people work hard for a while, and then participants are given a chance to absorb and reflect on what they have discussed.

- Plan for the turning point from "Me" to "We": As participants share information, they start seeing the whole and not just a part. When all information and perspectives are discussed, and 
when people see how the parts of the community or organisation interact, then it is possible to change and to manage the interactions differently.

- Build in an opportunity for the "IF": Many of the change methods create an opportunity for the group to generate a vision of a preferred future into the design. They might ask: "What would we like to see happening in our community five years into the future?" The "IF" that is built into all of these methods asks participants to dream about what they would like the future to be like, what would be their best hope. The stretch between the current situation and the vision of the future creates a tension that can produce energy, action and commitment.

- Allow opportunities for efficacy and commitment: Other explanations of efficacy could be "exerting influence" or "feeling empowered", which means having the capacity to adequately produce a desired effect (Bunker \& Alban, 1997:226). All these methods are designed to empower participants by analysing and interpreting information, setting priorities, creating new approaches and developing action plans.

- Use the Zamboni principle: To run large groups there must be an effective infrastructure, meaning good logistics. It is crucial to make sure that these events run seamlessly - no glitches, no ruts and unexpected bumps - just like the ice at the skating rink after the Zamboni River in the US has gone by. Logistics include issues of room size, table and chair lay-out, room lighting, microphone system, the way the food is served, etc.

- The importance of the process: It is important to remember that the process is part of the product. As Bunker and Alban (1997:227) state: "It is not the events that comprise the change process, but the change process itself that counts." Selecting the right issue is important, but the process by which the participants are engaged to address the issue is most important.

\section{Role of facilitator and group of whole system processes}

The types of group interventions are formulated in such a way that they foster shared leadership, energy, commitment, interaction, and people's own problem-solving capacities. Self-management and leadership roles, which can be shared, are also important for whole system processes. According to Leuci (2000), the following roles are relevant:

- A discussion leader, who ensures that each person who wants to speak is heard within the time available. He/she must help to keep the group on track to finish in time;

- A timekeeper keeps the group aware of the time left, monitors reporters and signals the time remaining to the person who is talking;

- A recorder sees that all flip charts are labelled and writes the group's output onto flip charts, using the speakers' own words;

- A reporter synthesises the output of the group and delivers the report to the large group in the time allocated;

- A data manager ensures that all flip charts are properly labelled and posted, and helps to keep related information together on the wall.

Because the facilitator's role is of the utmost importance, he/she must be trained in this approach before applying this model in the field. The facilitator takes on an "invisible" role as he/she only structures the main events in the process, rather than also structuring or dictating the type of content that participants should produce. The "invisible" facilitator tries to focus as little attention on him/herself as possible, in order to focus the attention of the community on itself, so that the 
process of introspection starts as the community reflects on itself. His/her focus must primarily be on helping individuals within the community to interact and connect, while remaining as unobtrusive as possible. He/she must have respect for human beings, accept people as they are, and believe in the self-determination of the community. Furthermore, the facilitator must be an expert in helping people and systems connect with each other in meaningful ways. The new paradigm rests on connecting, and people who can connect meaningfully and functionally will build a community. The facilitator must be able to help community members enter into true dialogue with each other.

\section{Steps of a large group intervention method: Vision to action: Take charge too}

During 2000 and 2001 the author attended three week-long training courses, focusing on this approach. Two of these courses were presented by the Community Development Academy in South Africa and the third by Missouri-Columbi in the USA.

The following large group intervention methods were then introduced to the Masters of Social Work students at the University of Johannesburg (previously RAU), during a workshop in February 2004: the Open Space Technology, the Conference Model, Appreciative Inquiry and Vision to Action: Take Charge Too. The latter method, viz. Vision to Action: Take Charge Too, was presented in depth to the students. Thereafter, the students applied this method in their various urban and rural settings.

The method, Vision to Action, consists of six steps, namely (1) Purpose; (2) detailing a Vision for the future; (3) organisation of vision into Themes; (4) move from Vision to Action Planning; then (5) Action Planning by choosing projects for further planning and development; and (6) Implementation for Sustainability.

Step 1: Purpose of Community Development. The first activity during the workshop is to ask the residents questions such as: Why does the community exist? What are the values expressed? What is development? The purpose of this step is to let people realise that community development is a shared responsibility and to start creating a feeling of "we".

Step 2: Vision: The next step consists of taking participants, as individuals, through a visualisation exercise, in which they imagine the perfect community, a situation where everything happens almost perfectly. The following scenario is usually given to the participants. It is the year 2015 . The community has become your concept of the ideal place where you would like to live. Describe what the community is like: its characteristics, functions, etc. The process starts by focusing on the personal vision of each person and is later compiled into a shared vision. Senge (1999) states that shared visions emerge from personal visions. This is how people derive their energy and how they foster commitment. If people don't have their own visions, all they can do is "sign up for someone else's. The result is compliance, never commitment." Shared vision originates from people sharing their own visions and learning to listen to the visions of others - from this listening gradual insights into what is possible gradually emerge.

Step 3: Vision Themes: From the various vision statements compiled by small groups of three to five people per group during step 2, major topics or sub-themes are identified.

Step 4: Vision to Action Planning: The facilitator places a piece of newsprint for each of the themes in different places in the room. Each member is asked to use his feet and proceed to the theme that he feels is an important and relevant issue in his own life. They are then asked to individually write three aspects needed to be addressed to minimise the risk of these obstacles in order to move to the desired vision for their community, related to their chosen theme area. Members are then requested to make a composite list of activities on a flipchart / newsprint. 
Step 5: Action Planning: Depending on the size of their group, members are then asked to choose activities for further planning and development. They have to consider the critical steps necessary to implement their solutions, the responsibilities of each member and the resources and information needed to carry out the activities. Each group then presents its solution plans to the rest of the larger group.

Step 6: Implementation for Sustainability: Each group is asked to work out an implementation plan - how it is going to be monitored, evaluated and sustained, when is the committee going to meet and when is feedback to be given to the community?

Before the six steps of the model can be applied, the establishment of a steering committee is of importance. Leuci et al. (1994) recommend the following criteria for choosing the steering committee: members should be representative of the cross-section of the organisation; members should have the time to participate; controversial people should not be included; involve people who are able to get things done; choose members who are able to access other people, networks and resources. It is important to assess the strengths and weaknesses of the steering committee members in order to make decisions about recruiting additional members.

The tasks of the steering committee would be to arrange the first workshops, and to then facilitate the implementation and activities highlighting the change process. It is also important that the steering committee keeps the community focused on the purpose and visionary plans at all times. The challenge is to keep the energy of people high by focusing on what people will do and not on how many projects there are. The steering committee should highlight contributors, note successes at every opportunity and celebrate these successes; capability must be assessed and ways to be inclusive, by bringing more and more people to the process, must be constantly monitored. Furthermore, it is important to revisit the purpose and to reconsider the vision on a regular basis, highlight what people are learning and seek continuous improvement.

\section{APPLICATION AND EVALUATION BY MASTERS STUDENTS}

The students went through the above six-step process by means of experiential training techniques, based on adult learning principles. The students applied and evaluated this model in both urban and rural communities. Ten Masters students were involved in various settings involving, among other aspects, aged people, HIV/Aids-infected and affected people, families connected to a daycare centre, high school learners connected to a youth club, residents of both rural and urban communities, and addressing crime and unemployment. Between 100 and 500 people attended the sessions. All the students established steering committees before the sessions to help with the preparations of these "planning-to-action" days.

The sustainability of the projects which resulted from this approach has not yet been evaluated, since the projects are still in development. However, formal, follow-up evaluations by the students are to be done at the end of this year.

Initially, the students were very sceptical about this asset-based approach. However, by applying the steps within the class environment, their attitudes started to change. After the application of the model in the various communities, the students are of the opinion that this paradigm is more suited to South African circumstances at this stage and time than the deficiency-based model.

The following initial preliminary findings can be reported from the informal, semi-structured interviews and observations used by the students in the evaluation of the model on ground level. Two main themes were identified, namely, the opinions of the community members who participated in the intervention model and the opinions of the students who were trained in this model. 


\section{Community participants}

The following aspects were identified by the community members who were part of the intervention model.

The level of participation throughout the workshops was high. The fact that the people were actively involved in matters that concerned them increased the level of participation.

The structuring of the tables and the fact that a group consisted of three to five people forced them to participate. As indicated by Bunker and Alban (1997), the arrangement of the tables plays an important role in the engagement, involvement and taking ownership of their projects by the people.

Whole system processes generated discussions, solutions, energy and productivity. People eagerly engaged in dialogue with other participants and seemed to find the process much more stimulating than other activities being presented in their communities. This aspect indicated that people want to be involved in a meaningful and authentic way in considering the future of their communities.

The process generated results in the form of practical plans and solutions.

Participants enjoyed the process very much, because it was based on their capacities, assets and strengths as opposed to needs and problems. The result was that much more enthusiasm was generated than with other programmes.

Because of the inclusive nature of this process, many more people, in various sections and on different levels in the community, were involved. They also engaged with role players on different levels and in different sections of the community. The interdisciplinary nature of the process therefore contributed to the fact that the people saw development as an integrated approach.

The emphasis on inclusiveness and communication also encouraged accountability.

The students have learnt to trust people to generate their own solutions and have seen that, without any theoretical knowledge, the solutions generated by the people are sometimes far better and more practical than the ones generated by experts in the organisation.

The students realised that this process requires a trained facilitator, who can be "invisible" and non-directive.

The focus on the future and building on strengths seemed to inspire hope and creativity. Participants appeared to make an investment in the process.

The process enhanced people's assertiveness and self-knowledge, whilst building their capacities and trust amongst each other.

This process indeed established a broad basis of leadership in the community.

\section{Training of students and other staff members}

The following aspects regarding the training in this model were identified:

Students and colleagues have to be trained in depth first before they will accept the approach and be able to transfer it to other target groups. One student, who involved colleagues in the process, was of the opinion that they had "trouble understanding the process and its application and had to experience a session with community people before they felt confident to help present". He continued: "Many social workers, even though they are trained in the values of social work, have a very limited mindset, one very much based on the old directive, expert model". 
If the trainer does not apply the steps of the model in depth in the training session, trainees will not have a full understanding of the model and will not be successful in the application of it in practice.

The trainer must make use of experiential training methods and adhere to basic adult education principles.

\section{CONCLUSION}

In the past, the future was often viewed as predictable and known, or as a straight-line extension of the past, through the present, into the future. Because of this, the use of felt needs and problem solving was felt to be appropriate. What makes the current situation different and disjunctive is that society has entered a period of major transformation. During periods of social transformation, there is a decoupling of the future from the past and the present (Senge, 1999). Situations are neither known nor recurring, but are instead unknown and new (Wade, 1989). Therefore, the focus must shift from present context to future contexts.

The context and challenge of development is no longer one of adaptation to what is, but one of fundamental transition to a new social and economic order. Community development of the 1960s is still an excellent way to assist people in improving their present social amenities, but it has become irrelevant to the broader, more central challenge of creating a new future. To be in line with the major transformations in the world and to address the challenges this presents, the practices and techniques of community development must be geared towards these transformations. The challenge for community development practitioners is to change from working with a maintenance system of programme design and delivery, reflecting felt needs and problems, to a proactive system based on anticipatory needs and vision. To do this the present reliance on felt needs and problem programming must be replaced by a diverse set of futuring, anticipatory and inspiring techniques.

In conclusion, it can be said that this approach holds much promise. It definitely has the potential to increase the commitment and energy of individuals in organisations and communities to take responsibility for their own development. It also helps in connecting people with each other and, in this way, increases general feelings of social support at work and at home. It builds the confidence of individuals and the ability of communities to really contribute functionally to their own lives.

\section{BIBLIOGRAPHY}

BUNKER, B.B. \& ALBAN, B.T. 1997. Large group interventions, engaging the whole system for rapid change. San Francisco: Jossey-Boss Publishers.

BURKEY, S. 2000. People first, a guide to self-reliant participatory rural development. Pretoria: Zed Publishers.

CHAMBERS, R. 1983. Rural development, putting the last first. England: Longman Scientific \& Technical.

CRONJÉ, G.J. DE J., DU TOIT, G.S. \& MOTLATLA, M.D.C. 2004. Introduction to business management $\left(6^{\text {th }}\right.$ ed). Cape Town: Oxford University Press.

DU TOIT, A.S., GROBLER, H.D. \& SCHENK, C.J. 1998. Person-centred communication, theory and practice. Johannesburg: Thomson Publishing.

FREIRE, P. 1994. Pedagogy of the oppressed. New York: Continuum. 
GRAY, M. \& COLLETT VAN ROOYEN, C.A.J. 2002. The strengths perspective in social work: lessons from practice. Social Work/Maatskaplike Werk, 38(3):193-201.

GREEN, G.P. \& HAINES, A. 2002. Asset building and community development. London: Sage Publications.

HESSELBEIN, F., GOLDSMITH, M. \& BECKARD, R. 1996. The leader of the future, new visions, strategies and practices for the new era. San Francisco: Jossey-Boss Publishers.

HOLLIS, F. 1966. Casework: a psychosocial therapy. New York: Random House.

HOLMAN, P. \& DEVANE, T. 1999. The change handbook, group methods for shaping the future. San Francisco: Berrett-Koehler Publishers, Inc.

KRETZMANN, J.P. \& McKNIGHT, J.L. 1993. Building communities from the inside out, a path toward finding and mobilizing a community's assets. Evanston: Center for Urban Affairs and Policy Research.

LEUCI, M.S. 2000. Large group interventions for whole system participation, development and change. Community Development Practice, No. 7: Community Development Society.

LEUCI, M.S., WADE, J.L., HACKMAN, D., MCCALL, J. \& LITTRELL, D. 1994. Community futures. Training manual. University of Missouri-Columbia.

McLAGAN, P. \& NEL, C. 1995. The age of participation, new governance for the workplace and the world. Randburg: Knowledge Resources (Pty) Ltd.

PERLMAN, H.H. 1957. Social casework: a problem-solving process. Chicago: The University of Chicago Press.

POWERS, R.C. 2001. Saline county study: A case study of community-based decision making. Paper presented at the $33^{\text {rd }}$ Annual Conference, Community Development Society, July 22-25, Duluth, US.

ROGERS, CR. 1989. Client centred therapy. London: Constable.

SCHUlTZ, H., BAGRAIM, J., POTGIETER, T., VIEDGE, C. \& WERNER, A. 2003. Organisational behaviour, a contemporary South African perspective. Pretoria: Van Schaik Publishers.

SENGE, P.M. 1999. The fifth discipline, the art and practice of the learning organisation. London: Random House Business Books.

SMIT, P.J. \& CRONJE, G.J. DE J. 2000. Management principles, a contemporary edition for Africa ( $2^{\text {nd }}$ ed). Kenwyn: Juta.

SUNTER, C. 1999. Never mind the millennium, what about the next 24 hours? Cape Town: Human \& Rousseau Tafelberg.

WADE, J. 1989. Felt needs and anticipatory needs: reformulation of a basic community development principle. Journal of the Community Development Society, (2)1:116-123.

WADE, J. 2000. Building communities from the grassroots. Training manual: Community Development Academy, South Africa. 
WEISBORD, M. \& JANOFF, S. 2000. Future search, an action guide to finding common ground in organizations and communities. San Francisco: Berrett-Koehler Publishers.

WHEATLEY, M.J. 1999. Leadership and the new science, discovering order in a chaotic world. San Francisco: Berrett-Koehler Publishers.

WHITE PAPER FOR SOCIAL WELFARE. 1997. Principles, guidelines, recommendations, proposed policies and programmes for developmental social welfare in South Africa. Pretoria: Department of Welfare.

Prof Hanna Nel, Professor in the Department of Social Work, University of Johannesburg, Auckland Park, South Africa. 